\title{
Nitrogen Mineralization Modeling in Some Upland Soils in the Western Region of Thailand
}

\author{
Busarin Swanglap ${ }^{1}$, Chawalit Hongprayoon ${ }^{2} \&$ Sunchai Phungern $^{2}$ \\ 1 Agricultural Research and Development Program, Faculty of Agriculture, Kasetsart University, \\ Kamphaengsaen Campus, Thailand \\ ${ }^{2}$ Department of Soil Science, Faculty of Agriculture, Kasetsart University, Kamphaengsaen Campus, Thailand \\ Correspondence: Chawalit Hongprayoon, Department of Soil Science, Faculty of Agriculture, Kasetsart \\ University, Kamphaengsaen Campus, Nakhon Pathom, 73140, Thailand. E-mail: agrclh@ku.ac.th
}

Received: April 28, 2015

Accepted: May 17, 2015

Online Published: September 30, 2015

doi:10.5539/mas.v9n11p235

URL: http://dx.doi.org/10.5539/mas.v9n11p235

The research is financed by Kasetsart University Research and Development Institute (KURDI).

\begin{abstract}
A laboratory aerobic incubation experiment was conducted to assess the influence of plant residue, soil moisture content, and soil types on mineralization of organic $N$. The experimental design was a $2 \times 3 \times 5$ factorial arrangement in a Randomized Complete Block design (RCBD) with three replications. The three factors were (1) two levels of plant residue ( 0 and 4 ton/rai of grinded cassava shoot), (2) three levels of soil moisture (PWP, $1 / 2$ AWCA, and FC), and (3) Five upland soil series of the Western region of Thailand, consisting of three main soil textures (fine, medium, and coarse texture). Nitrogen mineralized from native and added organic matter was examined at specific time intervals for 1 year. The data was fitted to a logistic mathematical model describing the relation between mineral $\mathrm{N}$ versus moisture content $(\theta)$, level of plant residue (PR), and time (t). The model was verified by predicting the amount of mineral $\mathrm{N}$ released under a given condition and the result was compared to the observed value under the same condition. Application of the model for field condition where soil moisture fluctuates was performed by differentiating the original model to obtain the relation between rate of mineral $\mathrm{N}$ production versus $\mathrm{N}(\mathrm{t})$, which was the implicit function of $\theta$, PR, and $t$. Stepwise calculation of the cumulative mineral $\mathrm{N}$ with time was developed to predict the amount of $\mathrm{N}$ mineralized through time. The results revealed that addition of 4 ton/rai plant residue drastically increased mineral $\mathrm{N}$ by 3.6 folds. The effect of soil moisture content and mineralization of organic $\mathrm{N}$ confirmed the significance of water on microbial activities. A satisfactory result was obtained from the mathematical model verification. The $\mathrm{b}$ and $\mathrm{R}^{2}$ values were close to 1.0 and the t-test were non-significant. A rather high value of Root Mean Squared Error (RMSE) was obtained contributing to the cycles of microbial population fluctuation. Application of the model to the condition of fluctuating soil water content was performed and compared to the observation value at a given level of plant residue application and soil water content.
\end{abstract}

Keywords: incubation period, mathematical modeling, $\mathrm{N}$ mineralization, plant residue, soil moisture content

\section{Introduction}

Soil nitrogen $(\mathrm{N})$ availability has significant influences on plant growth, and limits net primary productivity (Cole et al., 2008). Nitrogen available for crops, however, has to release from soil organic matter via microbial decomposition process, thus the recommendation for nitrogen fertilizer application rate in cropping system used the content of soil organic matter as the criterion for rough estimate. Since the two major factors affecting microbial decomposing process are soil aeration and soil moisture content. Assessment of the effects of both factors on nitrogen mineralization from organic matter is considered to be the major index for nitrogen mineralization model development. The incubation process consists of providing optimum condition for microbial decomposition process to obtain the maximum mineralization rates. Soil conditions were optimized by addition of water, nutrients, limestone and other inputs that enhance the activities of mineralizing organisms.

The soil nitrogen mineralization potential was evaluated as a function of time.

Estimating the $\mathrm{N}$ mineralization potential of a soil is a critical importance for maximizing $\mathrm{N}$-use efficiency and 
minimizing environmental losses. Efforts to develop quick biological or chemical methods for identifying the mineralization potential of organic $\mathrm{N}$ have a long history (reviewed by Bremner, 1965; Keeney, 1982; Bundy and Meisinger, 1994; Griffin, 2008) The evaluation of N availability may be achieved by means of short term biological methods using soil sample incubation in laboratory have been done to estimate the potentially mineralizable nitrogen in soil as a basis for making $\mathrm{N}$ fertilizers recommendations for crops (Foth \& Ellis, 1988).

Using empirical models it is possible to report and predict the relationships among events taking place in nature by fitting mathematical equations to experimental data (Camargo et al., 2002). To evaluate nitrogen mineralization dynamics in the soil, it is important to know which model best describes how this phenomenon is related to time. N mineralization in soil, according to Stanford and Smith (1972). The mechanistic models is process-based and generally requires considerable input data. The models normally rely on laboratory incubations to obtain parameters and do not account for basic $\mathrm{N}$ turnover processes such as mineralization, immobilization, and nitrification (Benbi and Richter, 2002).

Understanding of the quantitative relationships between soil moisture content and $\mathrm{N}$ mineralization rate in soils with different textures is essential as a basis for controlling the amounts of mineral $\mathrm{N}$ released to crops under specific soil moisture content. Therefore, it is very important to investigate the optimum moisture level for different soil textures at which $\mathrm{N}$ mineralization will be maximum. Our objectives were to study the effects of soil type, soil moisture, and rate of plant residue application on time course mineralization of organic $\mathrm{N}$. Mathematical model describing the relation between mineral $\mathrm{N}$ versus soil moisture, rate of plant residue application and time was expected for each soil. Chance to modify such the model for field condition where a soil moisture content change with time was also investigated.

\section{Materials and Methods}

\subsection{Soil Sample Collection and Preparation}

Five composite soil samples of 3 different textural classes were collected from the depth of 0-20 cm from the Western region of Thailand. Yang Talat (Yl) and Korat (Kt) soil series represented the course texture soil, whereas LatYa (Ly) and Kamphaeng Saen (Ks) soil series represented the medium textured soils and Pak Chong soil series $(\mathrm{Pc})$ represented the fine texture soil. Soil properties were shown in Table 1.

Table 1. Some characteristics of the soil used.

\begin{tabular}{lccccc}
\hline \multirow{2}{*}{ Soil texture } & \multicolumn{3}{c}{ Coarse } & \multicolumn{3}{c}{ Medium } & Fine \\
\cline { 2 - 6 } Properties & Sandy loam & Loamy sand & Sandy clay loam & Loam & Clay \\
& & & & & \\
& $(\mathrm{Kt})$ & $(\mathrm{Yl})$ & $(\mathrm{Ly})$ & $(\mathrm{Ks})$ & $(\mathrm{Pc})$ \\
\hline Field capacity $(\%, \mathrm{w} / \mathrm{w})$ & 0.074 & 0.048 & 0.112 & 0.163 & 0.199 \\
Permanent wilting point $(\%, w / w)$ & 0.017 & 0.013 & 0.057 & 0.087 & 0.167 \\
AWCA (\%,w/w) & 0.058 & 0.035 & 0.055 & 0.075 & 0.032 \\
Sand (\%) & 67.91 & 79.13 & 56.53 & 31.72 & 11.74 \\
Silt (\%) & 26.31 & 16.34 & 23.20 & 43.07 & 12.12 \\
Clay (\%) & 5.78 & 4.54 & 20.27 & 25.21 & 76.13 \\
Bulk density & 1.508 & 1.498 & 1.436 & 1.449 & 1.411 \\
pH in water (1:1, soil : water) & 5.43 & 5.58 & 6.33 & 7.86 & 5.26 \\
EC & 0.41 & 0.16 & 0.89 & 0.84 & 0.38 \\
OM (\%) & 0.45 & 0.38 & 1.58 & 1.38 & 2.52 \\
Total N (\%) & 0.03 & 0.026 & 0.063 & 0.073 & 0.085 \\
$\mathrm{NH}_{4}^{+}-\mathrm{N}\left(\mathrm{mg} \mathrm{kg}^{-1}\right.$ soil) & 0.11 & 0.13 & 0.25 & 0.23 & 0.19 \\
$\mathrm{NO}_{3}^{-}-\mathrm{N}\left(\mathrm{mg} \mathrm{kg}^{-1}\right.$ soil) & 0.22 & 0.11 & 0.27 & 0.34 & 0.25 \\
\hline
\end{tabular}

\subsection{Plant Material Preparation}

Oven dried cassava shoot grinded through $1 \mathrm{~mm}$ sieve was used as plant residues (PR) for adding into the soil.

Plant residue was mixed into soil at the rate of 0 and 4 ton/rai $\left(1 \frac{t o n}{r a i}=6.25 \frac{t o n}{h a}\right)$ before incubation. The analysis of plant residues was shown in Table 2 . 
Table 2. Chemical characteristics of plant residue used.

\begin{tabular}{lcccccccc}
\hline Plant residues & $\begin{array}{c}\mathrm{OM} \\
(\%)\end{array}$ & $\begin{array}{c}\text { Total N } \\
(\%)\end{array}$ & $\begin{array}{c}\text { Total C } \\
(\%)\end{array}$ & $\mathrm{C}: \mathrm{N}$ ratio & $\begin{array}{c}\mathrm{NH}_{4}^{+} \\
\left(\mathrm{mg}^{+} \mathrm{kg}^{-1}\right)\end{array}$ & $\begin{array}{c}\mathrm{NO}_{3}^{-} \\
\left(\mathrm{mg}^{-1} \mathrm{~kg}^{-1}\right)\end{array}$ & $\begin{array}{c}\text { Avail.K } \\
\left(\mathrm{mg} \cdot \mathrm{kg}^{-1}\right)\end{array}$ & $\begin{array}{c}\text { Avail.P } \\
\left(\mathrm{mg}^{-1} \mathrm{~kg}^{-1}\right)\end{array}$ \\
\hline Tapioca shoot & 90.95 & 6.72 & 45.78 & 6.82 & 16.19 & 17.54 & 0.52 & 3.15 \\
\hline
\end{tabular}

\subsection{Experimental Design}

The experimental design was a $2 \times 3 \times 5$ factorial arrangement in a Randomized Complete Block design (RCBD) with three replications. The three factors were (1) two levels of plant residue ( 0 and 4 ton/rai of grinded cassava shoot), (2) three levels of soil moisture (PWP, $1 / 2$ AWCA, and FC), and (3) Five upland soil series of the Western region of Thailand, consisting of three main soil textures (fine, medium, and coarse texture).

\subsection{Incubation Procedure and Chemical Analysis}

The incubation was carried out in plastic bottles each of $600 \mathrm{ml}$ capacity. The soil sample amounted to $200 \mathrm{~g}$ mixed with plant residue at 0 and 4 ton/rai was adjusted to field capacity (FC), $1 / 2$ available water capacity $(1 / 2$ AWCA), and permanent wilting point (PWP) with deionized water. Five small holes were drilled on a bottle lid to allow free gas exchange to prevent anaerobic condition. The bottles were incubated in laboratory condition under ambient temperature $\left(25-35^{\circ} \mathrm{C}\right)$ for 1 year. Soil moisture in the bottle was kept constant by means of periodic weighing. Deionized water was added to maintain the bottle to its original weight. Extractable mineral $\mathrm{N}\left(\mathrm{NH}_{4}{ }^{+}\right.$and $\left.\mathrm{NO}_{3}{ }^{-}\right)$in the soil was determined after the specified incubation period $(0,1,5,10,15,20,25,30$, $45,60,90,120,150,180,210,240,270,300,330,360$ days).

\subsection{Mathematical Modeling}

Mineral $\mathrm{N}$ was calculated from summation of $\mathrm{NH}_{4}{ }^{+}$and $\mathrm{NO}_{3}{ }^{-}$and plotted against time for each soil. Characteristics of variation suggested that the logistic mathematical model having and initial differential equation as shown in equation (1) might be used to represent such the relation.

$$
\frac{\mathrm{dN}}{\mathrm{dt}}=\mathrm{r}\left(\mathrm{N}_{\max }-\mathrm{N}(\mathrm{t})\right) \mathrm{N}(\mathrm{t})
$$

Where $\mathrm{dN} / \mathrm{dt}$ designated the rate of change of mineral $\mathrm{N}$ with time, $\mathrm{N}_{\max }$ was the maximum mineral $\mathrm{N}$ at the end of incubation period and $\mathrm{r}$ is a constant. Integration of equation (1) yielded logistic model as given in equation (2).

$$
\mathrm{N}(\mathrm{t})=\frac{\mathrm{N}_{0} \mathrm{~N}_{\max }}{\mathrm{N}_{0}+\left(\mathrm{N}_{\max }-\mathrm{N}_{0}\right) \mathrm{e}^{-\mathrm{rN} \max }}
$$

Where $\mathrm{N}_{0}$ was the mineral $\mathrm{N}$ at time $\mathrm{t}=0$ Matlab software was then employed to fit equation (2) to the observed data points of mineral $\mathrm{N}$ for each soil with time under a given level of soil moisture and plant residue application. The output parameters; $\mathrm{N}_{0}, \mathrm{~N}_{\max }$, and $\mathrm{r}$ obtained from the software were a set of 6 values according to 3 levels of soil moisture $\mathrm{x} 2$ levels of plant residue application. For $\mathrm{N}_{0}$ it was considered that it should not affected by levels of soil moisture and depended only on levels of plant residue (PR) so the values were averaged across soil moisture and graphed against plant residue application. The relation assumed straight line function illustrated in equation (3) Where $\mathrm{a}$ and $\mathrm{b}$ are constants.

$$
\mathrm{N}_{0}(\mathrm{PR})=\mathrm{a} \times \mathrm{PR}+\mathrm{b}
$$

By graphical technique $\mathrm{N}_{\max }$ and $\mathrm{r}$ were found to depend on both soil moisture according to second order polynomial functions illustrated in equations (4.1) and (4.2), respectively.

$$
\begin{gathered}
\mathrm{N}_{\max }=\mathrm{c} \times \theta^{2}+\mathrm{d} \times \theta+\mathrm{e} \\
\mathrm{r}=\mathrm{f} \times \theta^{2}+\mathrm{g} \times \theta+\mathrm{h}
\end{gathered}
$$

Where $\mathrm{c}, \mathrm{d}, \mathrm{e}$, and $\mathrm{f}, \mathrm{g}$, h were the relevant parameters. After fitting $\mathrm{N}_{\max }$ and $\mathrm{r}$ to variable $\theta$ by Matlab software these parameters were graphed against levels of plant residue and straight line functions were constructed according to equations (5.1)-(5.6) obtaining new sets of parameter $\mathrm{c} 1-\mathrm{h} 2$.

$$
\begin{aligned}
& c=c_{1} \times P R+c_{2} \\
& d=d_{1} \times P R+d_{2} \\
& e=e_{1} \times P R+e_{2} \\
& f=f_{1} \times P R+f_{2}
\end{aligned}
$$




$$
\begin{aligned}
& g=g_{1} \times P R+g_{2} \\
& h=h_{1} \times P R+h_{2}
\end{aligned}
$$

All sets of parameter were evaluated and plugged in equations (5.1)-(5.6) and then (4.1) and (4.2) to calculate $\mathrm{N}_{\max }(\theta, \mathrm{PR})$ and $\mathrm{r}(\theta, \mathrm{PR})$ as fully illustrated in equation (6.1) and (6.2).

$$
\begin{gathered}
\mathrm{N}_{\max }(\theta, \mathrm{PR})=\left(\mathrm{c}_{1} \times \mathrm{PR}+\mathrm{c}_{2}\right) \times \theta^{2}+\left(\mathrm{d}_{1} \times \mathrm{PR}+\mathrm{d}_{2}\right) \times \theta+\left(\mathrm{e}_{1} \times \mathrm{PR}+\mathrm{e}_{2}\right) \\
\mathrm{r}(\theta, \mathrm{PR})=\left(\mathrm{f}_{1} \times \mathrm{PR}+\mathrm{f}_{2}\right) \times \theta^{2}+\left(\mathrm{g}_{1} \times \mathrm{PR}+\mathrm{g}_{2}\right) \times \theta+\left(\mathrm{h}_{1} \times \mathrm{PR}+\mathrm{h}_{2}\right)
\end{gathered}
$$

Results obtained from equations (3), (6.1), and (6.2) were substituted in equation (2) to obtain the relation between mineral $\mathrm{N}(\mathrm{N}(\theta, \mathrm{PR}, \mathrm{t}))$ and soil moisture $(\theta)$, rate of plant residue application $(\mathrm{PR})$, and time $(\mathrm{t})$ according to equation (7).

$$
\mathrm{N}(\theta, \mathrm{PR}, \mathrm{t})=\frac{\mathrm{N}_{0}(\mathrm{PR}) \mathrm{N}_{\max }(\theta, \mathrm{PR})}{\mathrm{N}_{0}(\mathrm{PR})+\left(\mathrm{N}_{\max }(\theta, \mathrm{PR})-\mathrm{N}_{0}(\mathrm{PR})\right) \mathrm{e}^{-\mathrm{r}(\theta, \mathrm{PR}) \mathrm{N}_{\max }(\theta, \mathrm{PR}) t}}
$$

In equation (7) $N(\theta, P R, t)$ represented available $N$ (ammonium + nitrate) being mineralized into a given soil having applied with plant residue at the rate equal to PR and keeping water content at a constant value equal to $\theta$ evaluated at any time $t$. In using equation (7) plant residue can be applied at any rate from 0-4 ton/rai provided that soil water content is kept constant at any of the given 3 values; namely, field capacity (FC), $1 / 2$ available water capacity ( $\left.1 \frac{1}{2} \mathrm{AWCA}\right)$, and permanent wilting point (PWP).

\subsection{Validation Test for the Developed Mathematical Model}

Equation (7) was used to predict mineral $\mathrm{N}$ at specific time during course of incubation when the soil was applied with plant residue at given rate and by the way soil water content was kept at a given value. The result was then compared to the observed value at the same time. Difference between means of the observed and predicted value was verified by means of t-test and the point-to-point comparison was made by Root Mean Square Error (RMSE) as described in equation (8) (van Donk et al., 2004).

$$
\operatorname{RMSE}=\sqrt{\frac{\sum_{\mathrm{i}=1}^{\mathrm{n}}\left(\mathrm{y}_{\mathrm{i}} \hat{\mathrm{y}}_{\mathrm{i}}\right)^{2}}{\mathrm{n}}}
$$

Where $y_{i}$ and $\hat{y}_{i}$ were the observed and predicted values, respectively, and $\mathrm{n}$ was the number of observation.

Graphs were drawn between the observed and predicted values of mineral $N$, straight line functions were constructed and the accuracy and precision of the prediction were evaluated by the $\mathrm{b}$ and the $\mathrm{R}^{2}$ values of the functions.

\subsection{Application of the Constructed Mathematical Model}

In order to apply equation (7) to field condition where soil moisture changes with time the easiest way was to turned back to original differential equation as rewritten in equation (9).

$$
R(t)=\frac{d N}{d t}=r\left(N_{\max }-N(t)\right) N(t)
$$

In this equation $\mathrm{N}_{\max }$ and $\mathrm{r}$ were obtained from equation (6.1) and (6.2), respectively, if soil water content $(\theta)$ was known. If rate of plant residue application was decided the value of $\mathrm{N}_{0}$ can be calculated from equation (3). And as time (t) and the corresponding $\theta$ were known, $N(\theta, P R, t)$ can be calculated from equation (7). Now one can predict rate of plant residue decomposition $(\mathrm{R}(\mathrm{t})$ ) from equation (9). After decomposition rate was calculated as a function of average soil water content during specific time period $(\Delta t)$ the amount of mineral $N$ released during $\Delta \mathrm{t}$ could be calculated by $\Delta \mathrm{N}_{\mathrm{i}}=\mathrm{R}_{\mathrm{i}} \times \Delta \mathrm{t}_{\mathrm{i}}$ and cumulative mineral $\mathrm{N}$ released at time $\mathrm{t}\left(\mathrm{N}_{\text {cum }}\left(\mathrm{t}_{\mathrm{n}}\right)\right)$ could be calculated according to equation (10)

$$
\mathrm{N}_{\text {cum }}\left(\mathrm{t}_{\mathrm{n}}\right)=\sum_{\mathrm{i}=0}^{\mathrm{n}} \Delta \mathrm{N}_{\mathrm{i}}=\sum_{\mathrm{i}=0}^{\mathrm{n}} \mathrm{R}_{\mathrm{i}} \times \Delta \mathrm{t}_{\mathrm{i}}
$$

Where $R_{i}$ and $\Delta t_{i}$ were evaluated from equation (11.1) and (11.2), respectively

$$
\begin{aligned}
& \mathrm{R}_{\mathrm{i}}=\frac{\mathrm{R}\left(\mathrm{t}_{\mathrm{i}+1}\right)+\mathrm{R}\left(\mathrm{t}_{\mathrm{i}}\right)}{2} \\
& \Delta t_{i}=t_{i+1}-t_{i}
\end{aligned}
$$

In this case $R_{i}$ was the average value of decomposition rate between time $t_{i}$ to $t_{i+1}$ corresponding to water content $\theta_{i}$ and $\theta_{i+1}$, respectively. Also $\Delta t_{i}$ designated time duration between $t_{i}$ and $t_{i+1}$.

In using equation (10) one must select the plant residue application rate at the beginning of the season and monitor soil water content periodically through time then calculate $\mathrm{R}(\mathrm{t})$ by equation (9) using the value of $\theta$ 
being observed and then calculate $\mathrm{R}_{\mathrm{i}}$ and $\Delta \mathrm{t}_{\mathrm{i}}$ from equation (11.1) and (11.2), respectively. Up to this point one can calculate cumulative mineral $\mathrm{N}$ released from plant residue decomposition from equation (10).

\section{Results}

\subsection{Time Courses of Cumulative N Mineralization}

Nitrogen mineralization from native soil organic matter (treatments without plant residue addition) was low for each soil under every level of soil moisture maintained. Accumulations of nitrogen mineralized from native organic matter in course textured soils, $\mathrm{Kt}$ and $\mathrm{Yl}$ soil series, were low and difference was detected among levels of soil moisture maintained. In medium and fine textured soils, Ly, Ks, and Pc soil series, N mineralization at FC and $1 / 2$ AWC were higher than at PWP incubation. Addition of plant residue at 4 ton/rai, however, drastically enhanced the level of mineralized $\mathrm{N}$ throughout the year. Mineral $\mathrm{N}$ released from added plant residue was approximately 3.59 folds as compared to control ( 0 ton/rai) on the average (Table 6$)$
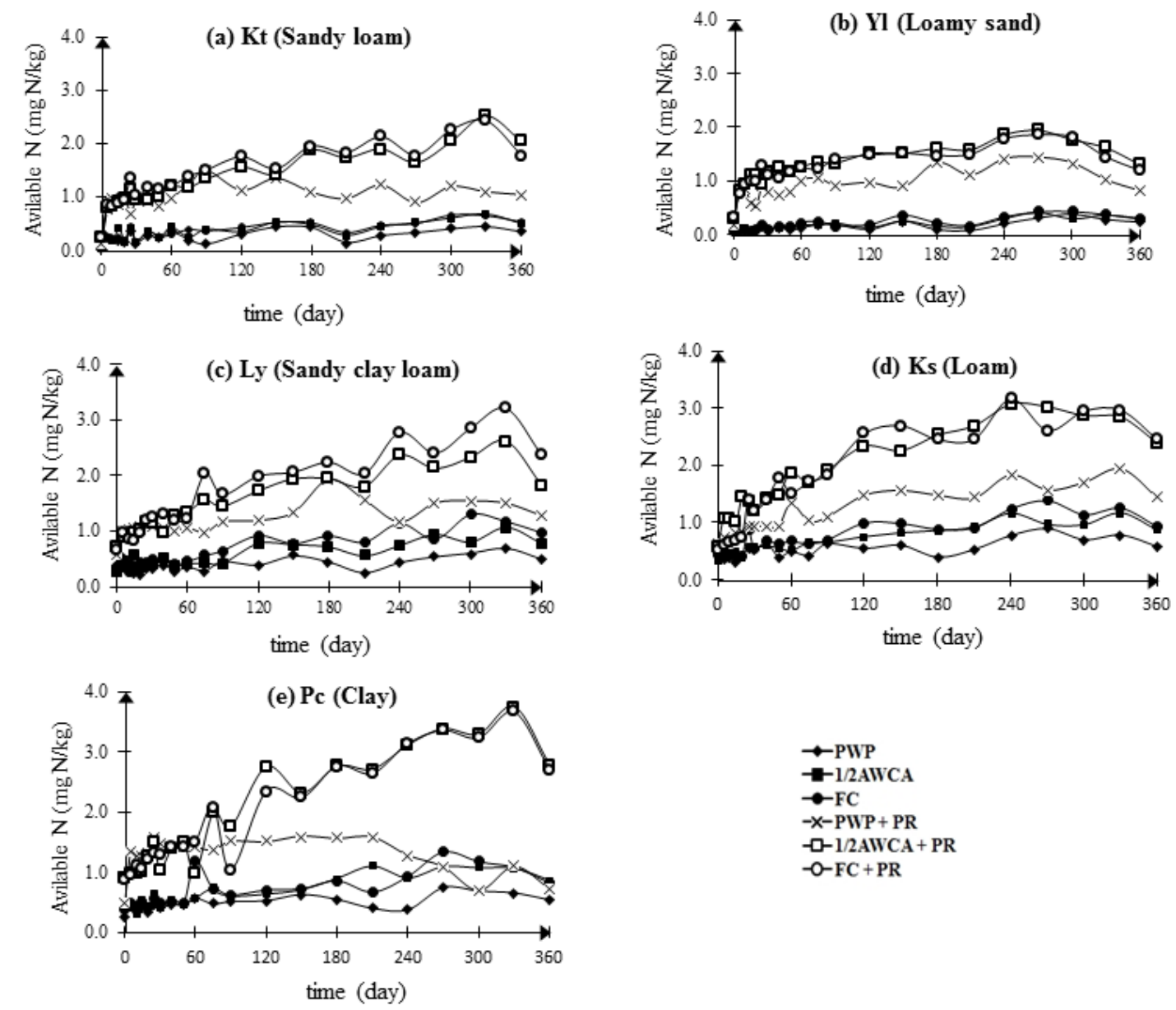

Figure 2. Time courses of cumulative mineral $\mathrm{N}$ during incubation of different soil type, soil moisture content and levels of plant residue; (a) Kt, (b) Yl, (c) Ly, (d) Ks, and (e) Pc

Rates of $\mathrm{N}$ mineralization from added plant residue were quite fast for short period at the beginning. The results were in agreement to Palm et al. (2001) that net $\mathrm{N}$ mineralization occurred right at the beginning in decomposition process of low C:N ratio plant residues. After short period of fast mineralization, the process were slowed down and maintained at relatively high rate compare to native soil if soil moisture content were maintain at FC and $1 / 2$ AWC. Mineralization at the restrict level of soil moisture at PWP, however, were carried out at low level similar to native soil (figure 2).

\subsection{Mathematical Modeling}

Graphs presented in figure (3) were depicted as an example for 5 soils amended with 4 ton/rai of plant residue and keeping water content at FC. Mineral $\mathrm{N}$ was observed to be rapidly released from plant residue at the beginning of incubation period and rate of release decreased materially after 150 days of incubation. Wavy 
pattern of response was noticed for $\mathrm{N}$ mineralization especially during later time course of incubation. This phenomenon might be contributed to a natural cycle of life and death of soil microorganisms. During the period of rapid population growth mineralization rate might be decreased and on the other hand during the period of population decline available $\mathrm{N}$ might be increased. The general pattern of response suggested that the Logistic mathematical model was suitable to describe the functions.
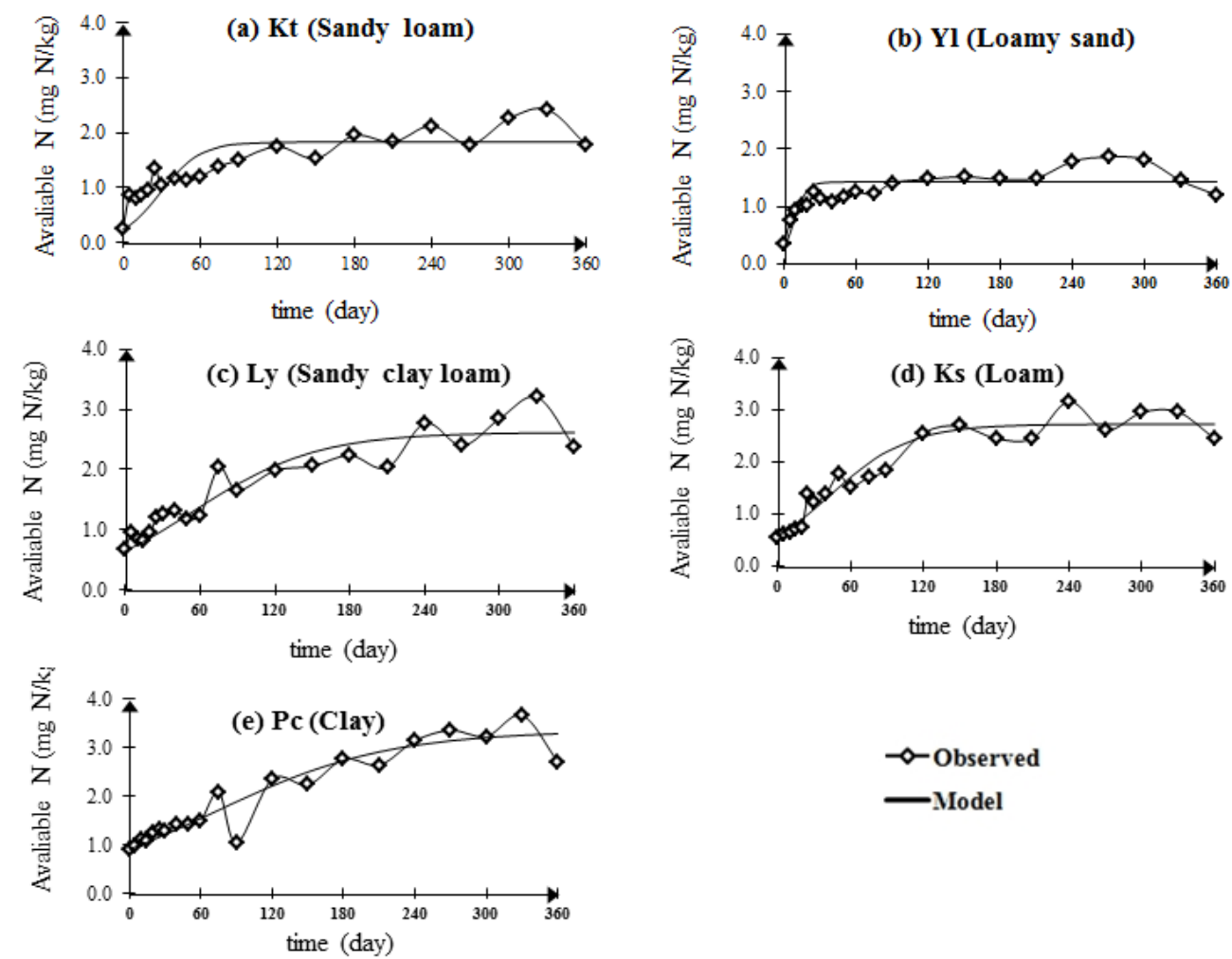

Figure 3. Time course variation of available $\mathrm{N}$ mineralization selected for 4 ton/rai residue application rate in soils; (a) Kt, (b) Yl, (c) Ly, (d) Ks, and (e) Pc as soil water content was kept constant at FC

As the relevant parameters in equations (2)-(5.6) were evaluated the results were presented in table (3). These parameters were then substituted in equations (3), (6.1), (6.2), and (7) to obtain mathematical function relating available $\mathrm{N}$ to soil water content $(\theta)$, level of plant residue application (PR), and time (t) for each soil. These functions were then used to calculate available $\mathrm{N}$ released from soils under the same condition of water content and rate of residue application. The result was shown as lined curve drawn in the same graph in figure (3). The predicted values were found to reflect the observed value on average. 
Table 3. The parameters of the mathematical model presented in equations (3)-(5.6) needed for calculation of parameters $\mathrm{N}_{0}, \mathrm{~N}_{\max }$ and $\mathrm{r}$ in equations (3), (6.1) and (6.2)

\begin{tabular}{cccccc}
\hline parameter & $\mathrm{Kt}$ & $\mathrm{Yl}$ & $\mathrm{Ly}$ & $\mathrm{Ks}$ & $\mathrm{Pc}$ \\
\hline $\mathrm{a}$ & 0.0530 & 0.0549 & 0.0784 & 0.0443 & 0.1404 \\
$\mathrm{~b}$ & 0.0267 & 0.0571 & 0.3377 & 0.4037 & 0.3557 \\
$\mathrm{c}_{1}$ & -98.600 & -119.760 & -97.322 & -86.063 & -477.080 \\
$\mathrm{c}_{2}$ & -52.570 & 3.755 & 31.008 & -9.107 & -1235.500 \\
$\mathrm{~d}_{1}$ & 11.6930 & 9.3050 & 21.7870 & 23.798 & 183.650 \\
$\mathrm{~d}_{2}$ & 7.651 & 0.231 & -2.562 & 7.107 & 466.020 \\
$\mathrm{e}_{1}$ & 0.021 & 0.106 & -0.852 & -1.207 & -17.066 \\
$\mathrm{e}_{2}$ & 0.167 & 0.299 & 1.050 & 0.269 & -42.807 \\
$\mathrm{f}_{1}$ & -208.060 & -38.856 & 9.058 & 1.342 & -30.372 \\
$\mathrm{f}_{2}$ & 943.240 & -5.225 & -0.331 & -5.332 & 145.510 \\
$\mathrm{~g}_{1}$ & 28.793 & 2.402 & -1.813 & -0.348 & 11.480 \\
$\mathrm{~g}_{2}$ & -128.160 & 2.159 & 0.196 & 1.383 & -55.115 \\
$\mathrm{~h}_{1}$ & -1.065 & -0.016 & 0.089 & 0.021 & -1.085 \\
$\mathrm{~h}_{2}$ & 4.647 & -0.001 & -0.008 & -0.073 & 5.222 \\
\hline
\end{tabular}

Statistical values presented in table (4) and figure (4) revealed that the slope (b) and the coefficient of determination $\left(\mathrm{R}^{2}\right)$ of the relation between observed and predicted mineral $\mathrm{N}$ were closed to 1 The result suggested that the two values were approximately the same. The point-to-point comparison by means of RMSE yielded values in the range of $0.17-0.22 \mathrm{mg} / \mathrm{kg}$ corresponding to the observed values in the range of $0.67-1.24$ $\mathrm{mg} / \mathrm{kg}$ which was quite high. The cycle of microbial population fluctuation was assumed to be the cause of this phenomenon. Comparison between means of observed and predicted values by means of t-test revealed no statistical difference between the two. The overall statistical tests suggested that the constructed mathematical models could meaningfully be used to predict the amount of available $\mathrm{N}$ mineralized from plant residue incorporated into the soils under the given conditions.

Table 4. Statistics of comparison between observed and predicted N-mineralization for each soil series

\begin{tabular}{lcccccccr}
\hline Soils & $\mathrm{b}$ & $\mathrm{R}^{2}$ & RMSE & mean observed & mean predicted & t-cal & t-table & Sig. \\
\hline $\mathrm{Kt}$ & 0.9330 & 0.8613 & 0.2227 & 0.7941 & 0.7540 & 0.5470 & 0.98 & $\mathrm{~ns}$ \\
$\mathrm{Yt}$ & 0.9676 & 0.9093 & 0.1708 & 0.6741 & 0.6638 & 0.1450 & 0.98 & $\mathrm{~ns}$ \\
$\mathrm{Ly}$ & 0.9618 & 0.9218 & 0.1833 & 1.0129 & 0.9852 & 0.3405 & 0.98 & $\mathrm{~ns}$ \\
$\mathrm{Ks}$ & 0.9756 & 0.9472 & 0.1738 & 1.1646 & 1.1376 & 0.2876 & 0.98 & $\mathrm{~ns}$ \\
$\mathrm{Pc}$ & 0.9806 & 0.9402 & 0.2068 & 1.2364 & 1.2220 & 0.1358 & 0.98 & $\mathrm{~ns}$ \\
\hline
\end{tabular}

\subsection{Application of the Constructed Mathematical Model}

In order to apply equation (7) to field condition where soil moisture content changes with time we constructed an arbitrary variation of soil water content with time of year as represented in table (5). Range of soil water content variation was confined between PWP and FC of each soil series. 


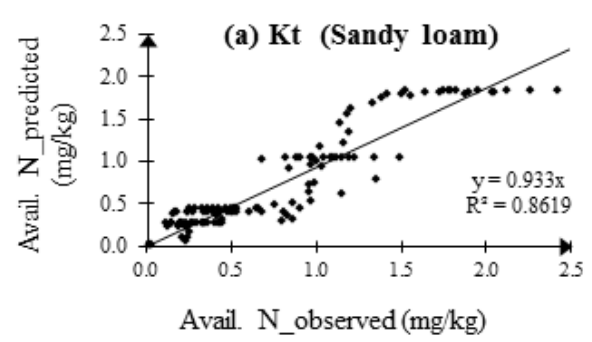

(c) Ly (Sandy clay loam)

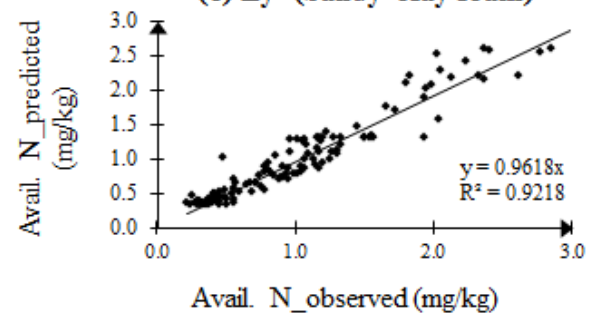

(b) Yl (Loamy sand)

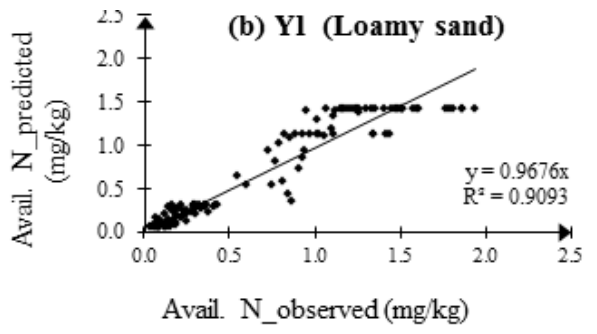

(d) Ks (Loam)

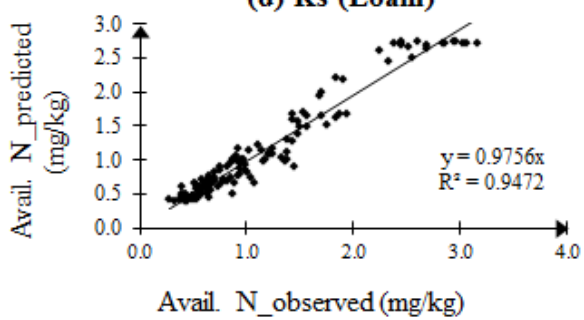

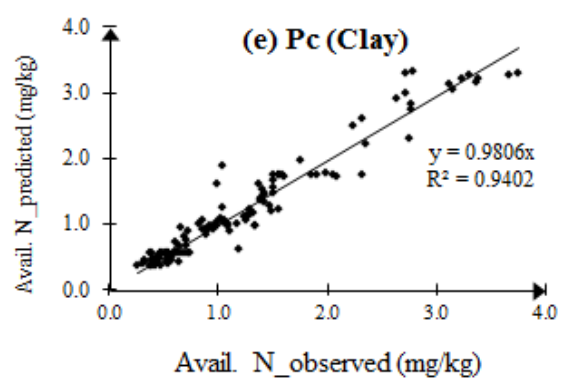

Figure 4. Relation between observed and predicted values of available N for soils; (a) Kt, (b) Yl, (c) Ly, (d) Ks, and (e) Pc

Table 5. Arbitrary monthly averaged soil water content throughout a year for difference soil series

\begin{tabular}{lcccccc}
\hline \multicolumn{1}{c}{ Month } & time (day) & $\mathrm{Kt}$ & $\mathrm{Yl}$ & $\mathrm{Ly}$ & $\mathrm{Ks}$ & $\mathrm{Pc}$ \\
\hline June & 0 & 0.037 & 0.025 & 0.077 & 0.103 & 0.178 \\
July & 30 & 0.049 & 0.033 & 0.088 & 0.119 & 0.185 \\
August & 60 & 0.061 & 0.040 & 0.100 & 0.135 & 0.192 \\
September & 90 & 0.073 & 0.048 & 0.111 & 0.151 & 0.199 \\
October & 120 & 0.082 & 0.053 & 0.120 & 0.163 & 0.204 \\
November & 150 & 0.082 & 0.053 & 0.120 & 0.163 & 0.204 \\
December & 180 & 0.061 & 0.040 & 0.100 & 0.135 & 0.192 \\
January & 210 & 0.025 & 0.018 & 0.065 & 0.087 & 0.172 \\
February & 240 & 0.025 & 0.018 & 0.065 & 0.087 & 0.172 \\
March & 270 & 0.025 & 0.018 & 0.065 & 0.087 & 0.172 \\
April & 300 & 0.025 & 0.018 & 0.065 & 0.087 & 0.172 \\
May & 330 & 0.025 & 0.018 & 0.065 & 0.087 & 0.172 \\
June & 360 & 0.037 & 0.025 & 0.077 & 0.103 & 0.178 \\
\hline
\end{tabular}

As an example of model application the level of plant residue application was assigned at 4 ton/rai. From the value of $\theta$ and the corresponding time $t$ one can calculate $R_{i}$ and $\Delta t_{i}$ as well as $N_{\text {cum }}\left(t_{n}\right)$ by the method mentioned earlier for each soil. The results were shown in figure 5 along with the observed value obtained as if soil moisture were kept constant at 1/2AWCA and PWP. 

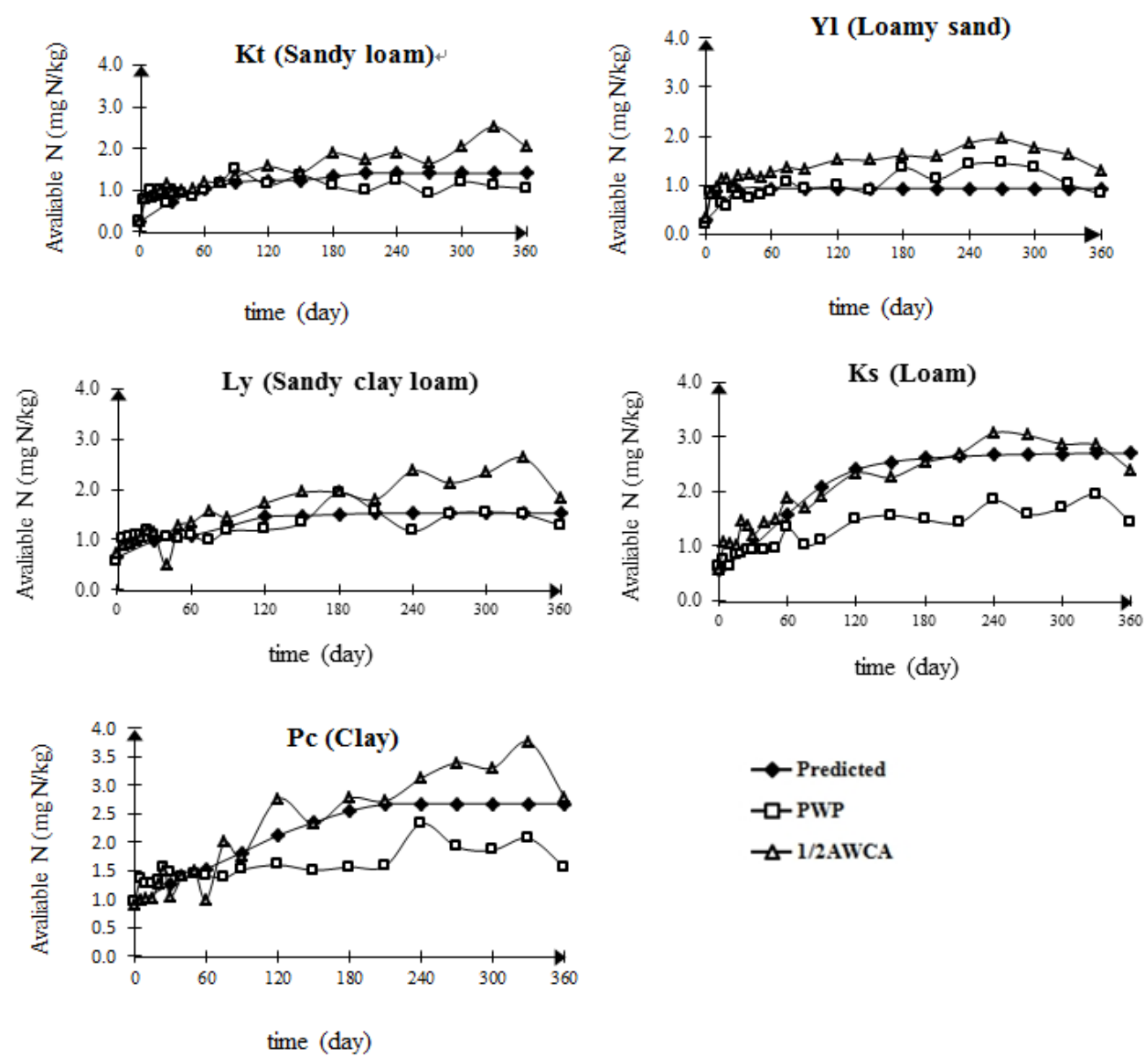

Figure 5. Predicted cumulative mineral $\mathrm{N}$ decomposed from organic residue with time as compared to the observed values if soil water content were kept constant at 1/2AWCA and PWP of each soil series

The predicted values of $\mathrm{N}_{\text {cum }}$ were noticed to fluctuate between the two limits suggesting that equation (10) could be used meaningfully to predict cumulative mineral $\mathrm{N}$ decomposed from plant residue under the situation where soil moisture changes with time. Since yearly averaged soil water content simulated was around $1 / 2$ AWCA $N_{\text {cum }}$ curve should resemble that of $1 / 2 \mathrm{AWCA}$ curve, however some of them were close to PWP curve. In the later cases especially for the soil having rapid early rate of decomposition might suffer from constraint of limited soil moisture during the beginning period as might be seen from table (5). Such the condition would suppress the decomposition rate and caused the predicted curves to resemble the PWP curves (figure 5).

\section{Discussion}

Effect of levels of plant residue on mineral $\mathrm{N}$ for each soil as presented in table (6) indicated that mineral $\mathrm{N}$ released from plant residue at 4 ton/rai was approximately 3.59 folds as compared to control $(0$ ton/rai) on the average. The observed value of mineral $\mathrm{N}$ was $1.50 \mathrm{mg} / \mathrm{kg}$ soil at the end of the experiment as compared to 0.49 $\mathrm{mg} / \mathrm{kg}$ soil of control treatment. It was noticed that the ratios of mineral $\mathrm{N}$ decomposed from 4 ton/rai treatment to control treatment of coarse textured soils (Kt and Yl) ranged between 3.74-6.39 and such the ratios of medium (Ly and Ks) and fine textured soils (Pc) were comparable and ranged between 2.41-2.73. The data suggested that if the native organic material of soils was the same decomposition in coarse textured soils would be higher than medium and fine textured soils, respectively. The nature of the decomposer population and available pore space has been found to influence the rate of mineralization of organic substrates added to soil (Srensen, 1975; Elliott et al., 1980; Hassink et al., 1993), However the difference of mineral $\mathrm{N}$ between plant residue rate of 4 ton/rai and control treatment revealed that decomposition of organic material in coarse and medium textured soils was about the same and ranged between $0.92-0.98 \mathrm{mg} / \mathrm{kg}$ soil noticeably smaller as compared to $1.23 \mathrm{mg} / \mathrm{kg}$ soil of fine textured soil (Pc). Magdoff (1991) showed that SOM level and soil-textured interact to influence availability of $\mathrm{N}$. At low soil $\mathrm{N}$ levels (and low SOM) in coarse-textured soil, mineralization rates are high but low amounts 
of organic $\mathrm{N}$ meant that little $\mathrm{N}$ is made available. The data suggested that level of native organic material influenced decomposition of plant residue input into soil. This might be because larger organic material content promoted diversified microbial species and larger microbial population and this in turn enhanced decomposition of native organic material contained in the soil. According to the study of Hassink et al.(1993), There are also a good correlation between the small pore fraction and the relative increase in $\mathrm{N}$ mineralization with fine sieving.

Table 6. Effect of plant residue application rates on mineral $\mathrm{N}$ decomposed $(\mathrm{mg} / \mathrm{kg})$ in tested soils averaging across different levels of soil moisture

\begin{tabular}{lcccc}
\hline \multicolumn{1}{c}{ Soil series } & ( (ton/rai) & 4 (ton $/$ rai) & Ratio & difference $(\mathrm{mg} / \mathrm{kg})$ \\
\hline Kt (Sandy loam) & 0.335 & 1.253 & 3.741 & 0.918 \\
Yl (Loamy sand) & 0.182 & 1.166 & 6.389 & 0.983 \\
Ly (Sandy clay loam) & 0.550 & 1.476 & 2.685 & 0.926 \\
Ks (loam) & 0.682 & 1.647 & 2.416 & 0.966 \\
Pc (clay) & 0.707 & 1.934 & 2.737 & 1.227 \\
\hline \multicolumn{1}{c}{ Avg. } & 0.491 & 1.495 & 3.594 & 1.004 \\
\hline
\end{tabular}

Influence of soil water content on mineral $\mathrm{N}$ as presented in table (7) revealed that higher decomposition was obtained from higher soil water content. At field capacity the observed mineral $\mathrm{N}$ was $1.13 \mathrm{mg} / \mathrm{kg}$ soil higher than 1.07 and $0.78 \mathrm{mg} / \mathrm{kg}$ soil at 1/2AWCA and PWP, respectively. This finding was consistent with other studies in the natural condition the net $\mathrm{N}$ mineralization rate was low at $20 \%$ WHC because the cellular desiccation of microbes occurred under low moisture conditions (Chen et al., 2011), agreement was found with that of Haynes (1986) which described that the decline in sizes and activities of decomposer community by the lethal action of moisture stress had a retarding effect on the process of decomposition. It was noticed that decomposition of fine textured soil (Pc) was higher than medium (Ly and Ks) and coarse textured soils (Kt and Yl) at every levels of soil moisture.

Table 7. Effect of soil moisture on mineral $\mathrm{N}$ decomposed $(\mathrm{mg} / \mathrm{kg})$ in tested soils averaging across different levels of plant residue application rates

\begin{tabular}{lccc}
\hline \multicolumn{1}{c}{ Soil series } & PWP & 1/2AWCA & FC \\
\hline Kt (Sandy loam) & 0.626 & 0.857 & 0.899 \\
Yl (Loamy sand) & 0.540 & 0.744 & 0.739 \\
Ly (Sandy clay loam) & 0.806 & 1.041 & 1.192 \\
Ks (loam) & 0.874 & 1.308 & 1.312 \\
Pc (clay) & 1.071 & 1.408 & 1.482 \\
\hline \multicolumn{1}{c}{ Avg. } & 0.783 & 1.072 & 1.125 \\
\hline
\end{tabular}

As seen from figure (2) the wavy pattern of mineral $\mathrm{N}$ variation with time caused by fluctuation of microbial population might responsible for high values of RMSE. The $b$ and $\mathrm{R}^{2}$ values of most soils were close to 1.0 except that of Kt soil (table 4). In fact the soil has the most rapid rate of decomposition during the first 30 days and the rate decreases materially during the following 90 days resulting lower estimation by the model during the first period and vice versa during the second period (figure 3). This phenomenon might cause lower accuracy and precision by the model as noticed by lower values of $b$ and $\mathrm{R}^{2}$ and high value of RMSE.

Average value of the parameters $\mathrm{N}_{0}, \mathrm{~N}_{\max }$, and $\mathrm{r}$ of the test soils were given in table (8). The initial value of mineral $\mathrm{N}$ was found to depend on soil texture. The coarser texture the lower the $\mathrm{N}_{0}$ and vice versa. The same trend was observed for the values of $\mathrm{N}_{\max }$ besides the difference between $\mathrm{N}_{\max }$ and $\mathrm{N}_{0}$ were roughly the same for all soils suggesting that the level of existing organic matter has pronounce effect on level of observed mineral $\mathrm{N}$. 
Table 8. Average value of the parameters $\mathrm{N}_{0}, \mathrm{~N}_{\max }$, and $\mathrm{r}$ of the test soils

\begin{tabular}{|c|c|c|c|c|c|}
\hline & \multicolumn{2}{|r|}{ Coarse } & \multicolumn{2}{|c|}{ Medium } & \multirow{2}{*}{$\begin{array}{l}\text { Fine } \\
\text { Clay } \\
(\mathrm{Pc})\end{array}$} \\
\hline & $\begin{array}{l}\text { Sandy loam } \\
(\mathrm{Kt})\end{array}$ & $\begin{array}{l}\text { Loamy sand } \\
\text { (Yl) }\end{array}$ & $\begin{array}{l}\text { Sandy clay loam } \\
\text { (Ly) }\end{array}$ & $\begin{array}{l}\text { Loam } \\
(\mathrm{Ks})\end{array}$ & \\
\hline $\mathrm{N}_{0}$ & 0.1543 & 0.1669 & 0.4946 & 0.4924 & 0.6365 \\
\hline $\mathrm{N}_{\max }$ & 1.1058 & 0.8183 & 1.5598 & 1.6864 & 1.8578 \\
\hline $\mathrm{r}$ & 0.2717 & 0.0858 & 0.0160 & 0.0113 & 0.0211 \\
\hline
\end{tabular}

In table (8) the value of parameter $r$ of Kt soil was noticeably larger than the rest suggesting that decomposition rate of organic residue in this soil was mostly rapid during the first period because of good aeration of the soil but the decomposition rate is materially slow for the rest of the time because of substrate exhaustion.

Application of the constructed models to field condition was restricted within FC and PWP soil water content range. Applying the model to soil with water content lower than PWP might yield negative value of parameter $r$ and cause error in $\mathrm{N}_{\text {cum }}$ prediction. In this case where implication was aimed to lower range of soil moisture new set of experiment is recommended where air dried moisture content should be included as one of soil moisture treatment.

\section{Conclusion}

An experiment to evaluate the decomposition of mineral $\mathrm{N}$ from plant residue applied to soils at different levels of plant residue and at different levels of constant water content was conducted. Mineral $\mathrm{N}$ being released from plant residue was monitored along a time course of 1 year. The result revealed that an application rate at 4 ton/rai yielded significantly higher mineral $\mathrm{N}$ than control treatment. Higher decomposition of plant residue was found for soil water content at FC as compared to 1/2 AWCA and PWP, respectively, with a tendency that the first and the second levels of soil moisture produced comparable mineral N. Furthermore different levels of decomposition were found for different soils. Finer textured soils tended to have higher decomposition than medium and coarse textured soils, respectively.

A Mathematical model describing the amount of mineral $\mathrm{N}$ released with time assuming logistic model was found to yield predicted values close to the observed values for every test soil, levels of soil moisture, and plant residue application rate. The constructed model could be used to predict mineral $\mathrm{N}$ at any time $\mathrm{t}$, provided that soil water content was kept constant at any value between FC and PWP and a level of plant residue application at any value between $0-4$ ton/rai. In order to modify the model to cope with field situation where soil moisture may vary with time, the rate of mineralization was calculated by differentiation of the original function with respect to time. The new function described the relation between mineralization rate versus soil moisture, level of plant residue, and time. Steps of calculation were developed to obtain cumulative mineral $\mathrm{N}$ as a function of time. A simulation was conducted at 4 ton/rai of plant residue application and a given soil moisture fluctuation with time. The result was compared to the cumulative value of mineral $\mathrm{N}$ obtained under a 4 ton/rai application rate and constant soil water content at 1/2AWCA and PWP. The result suggested that the developed model could reasonably be used to predict mineral $\mathrm{N}$ decomposition at a given time.

\section{Acknowledgement}

We are grateful to Kasetsart University Research and Development Institute (KURDI) for financial support. Thanks are also due to the technical staff at the Department of Soil Science, Kasetsart University and Office of Science for Land Development Department.

\section{References}

Benbi, D. K., \& Richter, J. F. (2002). A critical review of some approaches to modeling nitrogen mineralization. Biol. Fertil. Soils, 35, 168-183. http://dx.doi.org/10.1007/s00374-002-0456-6

Bremner, J. M. (1965). Organic forms of nitrogen, p. 1238-1255. In C.A. Black et al. (Ed.), Methods of soil analysis. Agron.

Bundy, L. G., \& Meisinger, J. J. (1994). Nitrogen availability indices. In R.W. Weaver et al (Ed.), Methods of soil analysis (pp. 951-984). Part 2.SSSA Book Ser. 5. ASA and SSSA, Madison, WI.

Camargo, S. J., \& Zebiak, S. E. (2002). Improving the detection and tracking of tropical cyclones in atmospheric general circulation models. Wea. Forecasting, 17, 1152-1162. 
http://dx.doi.org/10.1175/1520-0434(2002)017<1152:ITDATO >2.0.CO;2

Chen, Y. R., Werner, B., \& Claus, F. S., et al. (2011). Effects of decreasing water potential on gross ammonification and nitrification in an acid coniferous forest soil. Soil Biology \& Biochemistry, 43(2), 333-338. http://dx.doi.org/10.1016/j.soilbio.2010.10.020

Cole, L., Buckland, S. M., \& Bardgett, R. D. (2008). Influence of disturbance and nitrogen addition on plant and soil animal diversity in grassland. Soil Biology \& Biochemistry, 40, 505-514. http://dx.doi.org/10.1016/j.soilbio.2007.09.018

Elliott, T. E., Anderson, R. V., Coleman, D. C., \& Cole, C. V. (1980). Habitable pore space and microbial trophic interactions. Oikos, 35, 327-335.

Griffin, T. S. (2008). Nitrogen availability. In J. S. Schepers, \& W. R. Raun (Ed.), Nitrogen in agricultural soils (pp. 616-646). Agron. Monogr.49.ASA, CSSA, SSSA, Madison WI.

Hassink, J., Bouman, L. A., Zwart, K. B., \& Brussard, L. (1993). Relationship between habitable pore space, soil biota and mineralization rates in grassland soils. Soil Biol. Biochem, 25, 47-55. http://dx.doi.org/10.1016/0038-0717(93)90240-C

Magdoff, F. R. (1991). Field nitrogen dynamics: Implications for assessing N availability. Comnum. Soil Sci. Plant Anal, 22, 1507-1517. http://dx.doi.org/10.1080/00103629109368511

Palm, C. A., Gachengo, C. N., Delve, R. J., Cadisch, G., \& Giller, K. E. (2001). Organic inputs for soil fertility management in tropical agroecosystems: Application of an organic resource database. Agric. Ecosyst. Environ, 83, 27-42. http://dx.doi.org/10.1016/S0167-8809(00)00267-X

Srensen, L. H. (1975). The influence of clay on the rate of decay of amino acid metabolites synthesized in soils during decomposition of cellulose. Soil Biol. Biochem, 7, 171-177. http://dx.doi.org/doi:10.1016/0038-0717(75)90015-2

Stanford, G., \& Smith, S. J. (1972). Nitrogen mineralization potentials of soils. Soil Sci.Soc. Am. Proc. 36, 465-472. http://dx.doi.org/10.2136/sssaj1972.03615995003600030029x

Tollner, E. W., Van Donk, S. J., Steiner, J. L., \& Evett, S. R. (2004). Soil temperature under a dormant Bermuda grass mulch: Simulation and measurement. Am. Soc. Agric. Eng. 47, 91-98.

\section{Copyrights}

Copyright for this article is retained by the author(s), with first publication rights granted to the journal.

This is an open-access article distributed under the terms and conditions of the Creative Commons Attribution license (http://creativecommons.org/licenses/by/3.0/). 